\title{
MELANIC POLYMORPHISM IN LADYBIRDS MAINTAINED BY SEXUAL SELECTION
}

\author{
PETER O'DONALD* and JOHN MUGGLETON $\uparrow$ \\ *Department of Genetics, University of Cambridge, Downing Street, Combridge CB2 $3 E H$; \\ †Ministry of Agriculture, Fisheries and Food, Pest Infestation Control Laboratory, London Road, \\ Slough, Berkshire SL3 7HJ.
}

Received 26.iii.79

\section{INTRODUCTION}

The two-spot ladybird, Adalia bipunctata, is polymorphic for a number of black, melanic forms and red, non-melanic forms. They are under the genetic control of at least 12 alleles, with melanics dominant to nonmelanics. Several different selective factors probably determine their relative frequencies which vary between populations in different environments (Muggleton, 1978). But this putative selection will not necessarily give rise to a balance of forces that would maintain the polymorphism. In a recent paper, however, Muggleton (1979) reported data showing frequency-dependent mating of the melanic and non-melanic forms. This sexual selection would certainly be sufficient to maintain the polymorphism in melanism. Frequency-dependent mating inevitably occurs if some individuals, usually females, prefer to mate with particular phenotypes (O'Donald, 1973, 1977a, 1977b). In a polygynous organism in which a certain number of matings are always preferential, the preferred individuals necessarily mate more often when they are rare since a relatively greater proportion of individuals prefer them.

Preferences expressed for more than one phenotype always produce a balance of mating advantage at a point of stable equilibrium. Alternatively, the frequency-dependent mating can be balanced by natural selection acting against the preferred phenotype; but to reach a point of balance, the mating advantage at low frequency must outweigh the adverse natural selection. Mating preferences may not be completely expressed; on the contrary, they may be expressed partially depending on the chances of encounter with the preferred individuals. An individual may encounter a number of possible mates who do not possess the preferred phenotype and finally mate at random regardless of the mate's phenotype. Models which allow for this partial expression of preference give rise to a reduced level of frequency-dependence in the mating advantage of the preferred types: individuals are less likely to be encountered at lower frequencies; preferences in their favour are less often expressed; the proportion of preferential matings is reduced; and being rare is less of an advantage. Even so, stable polymorphisms are still the general rule in these models (O'Donald, $1978 a, 1978 b)$.

In the most general model of the expression of mating preference (O'Donald, 1978a, 1979), females with preferences mate at random if they fail to encounter a male they prefer after $n$ successive encounters with courting males: after the $n$ unsuccessful encounters, they mate with the 
next male regardless of his phenotype. This leads to the following probabilities of mating when a dominant phenotype $(A)$ and a recessive $(a)$, at frequencies $\mathrm{I}-w$ and $w$, are the objects of the preference (O'Donald, 1978a):

$$
\begin{aligned}
& P(A)=\alpha\left(1-w^{n+1}\right)+\beta(1-w)^{n+1}+(1-w)(1-\alpha-\beta) \\
& P(a)=\alpha w^{n+1}+\beta\left[1-(1-w)^{n+1}\right]+w(1-\alpha-\beta)
\end{aligned}
$$

In this model, a proportion $\alpha$ prefer to mate with $A$, a proportion $\beta$ prefer to mate with $a$, and the remainder, $1-\alpha-\beta$, mate at random. An equilibrium is established at the phenotypic frequency

$$
w^{*}=\frac{\beta\left[1-\left(1-w^{*}\right)^{n}\right]}{\alpha\left(1-w^{* n}\right)+\beta\left[1-\left(1-w^{*}\right)^{n}\right]}
$$

For values of $n>\mathrm{I}$, the polymorphic equilibrium is stable (O'Donald, $1978 a$, 1979). Clearly, as $n \rightarrow \infty$, we have in the limit

$$
w^{*}=\beta /(\alpha+\beta)
$$

This is the phenotypic equilibrium frequency when mating preferences are completely expressed.

\section{Frequencies of matings of Ladybirds}

Muggleton (1979) collected random samples of ladybirds noting the morphs of copulating pairs. The sexes can be distinguished because the male is carried on the female's back during copulation. Similar samples had been collected in Potsdam by Meissner (1907a, 1907b, 1909). Muggleton carried out two tests of significance on the data: one for assortative mating; the other for differences in the frequencies of melanics in mating and nonmating individuals. In testing for assortative mating, it is necessary to separate the samples according to the frequency of the melanic morphs: since this frequency varies widely between the samples, the overall data would show a spurious assortment of the phenotypes. However, a test of the overall significance of the data can be carried out by calculating probabilities for the data of mating pairs in each of Muggleton's six frequency ranges. Then Fisher's combination of probabilities test gives $\chi^{2}=13.682$ for 12 degrees of freedom, corresponding to a level of significance at the probability $\mathrm{P}=0.322$. This confirms Muggleton's conclusion that the data provide no evidence for assortative mating of melanic and non-melanic phenotypes.

The numbers of melanics and non-melanics in mating pairs are very significantly different from their numbers among non-mating individuals. Muggleton (1979) calculated the cross-product ratio:

$$
\frac{\text { no. of non-melanic individuals }}{\text { no. of melanic individuals }} \times \frac{\text { no. of melanics in mating pairs }}{\text { no. of non-melanics in mating pairs }}
$$

The log of this ratio has a negative slope when plotted against the frequency of melanics showing that the melanics' mating success is relatively greater at lower frequency. At high frequencies of melanics, the non-melanics gain the selective advantage. These results show a frequency-dependent advantage of the rarer morph similar to the "rare-male effect" so exten- 
sively studied in laboratory experiments with Drosophila (for example, see Petit, 1954; Ehrman, 1967, 1968, 1972; Spiess, 1968; Ehrman and Spiess, 1969; Petit and Ehrman, 1969; Spiess and Spiess, 1969; Spiess and Ehrman, 1978). This suggests that Muggleton's data may fit the same models of mating preference that O'Donald $(1977 a, 1978 a)$ fitted to Ehrman and Spiess' data on Drosophila. Among the ladybirds, however, the rarer phenotypes of both sexes possess a similar advantage: sexual selection seems to operate with similar intensity on both males and females. The frequencies of matings of melanics and non-melanics do not differ significantly between the sexes. But this is not altogether surprising. Ladybirds are highly promiscuous. Females need to copulate many times to fertilise all the eggs they lay: presumably they must compete for males, just as the males compete to fertilise them.

\section{Results OF FITTING THE MODEL TO THE DATA}

Suppose that melanic and non-melanic ladybirds mate at frequencies given by the expressions for $P(A)$ and $P(a)$ as shown in the introduction to this paper. Then $\alpha$ will be the preference for melanics and $\beta$ the preference for non-melanics. If a proportion $m$ of the individuals in the population are mating at any one time, then we shall have the following frequencies of mating and non-mating ladybirds:

$\begin{array}{llll} & \text { Mating } & \text { Non-mating } & \text { Totals } \\ \text { Melanics } & m P(A) & 1-w-m P(A) & 1-w \\ \text { Non-melanics } & m P(a) & w-m P(a) & w \\ \text { Totals } & m & 1-m & 1\end{array}$

Each sample consists of the four classes of individual: mating and nonmating, melanic and non-melanic. If the marginal totals in each sample are considered to be fixed totals, then this implies that the maximum likelihood estimates of $m$ and $w$ have already been fitted to the data of each sample. Each sample then has 1 degree of freedom left for the estimation of the parameters $\alpha$ and $\beta$ for the preferences and $n$ for the number of encounters. The expression for the log likelihood for each sample is based on the frequencies of mating and non-mating individuals of the two morphs as shown above. The parameters $\alpha, \beta$ and $n$ are then estimated as the values that maximise the sum of the log likelihoods for all samples. These estimates of the parameters are therefore overall estimates, based on the data of all samples. They are used to calculate the numbers expected in each sample according to the frequencies given by the model. Thus we calculate a residual $\chi^{2}$ for the heterogeneity left in the data after the fitting of the model.

Table 1 (i) shows the data Muggleton collected in England and the results of fitting the model to the data. Table 1 (ii) shows the Potsdam data and results. The model with constant preferences (the case when $n \rightarrow \infty)$ fits the Potsdam but not the English data. The additional parameter $n$ significantly improves the fit of the model when estimated for the English data: $\chi^{2}$ is significantly reduced from 13.141 with 5 degrees of freedom $(\mathrm{P}=0.022)$ to 5.594 with 4 degrees of freedom $(\mathrm{P}=0.232)$ after fitting $n$. For the Potsdam data, however, $\chi^{2}$ is hardly reduced at all after fitting $n$ 
TABLE 1

Data of numbers of melanic $(M)$ and non-melanic $(\mathcal{N m})$ ladybirds found mating or not mating

(i) Data from England

\begin{tabular}{|c|c|c|c|c|}
\hline \multicolumn{5}{|c|}{ Numbers of ladybirds } \\
\hline \multicolumn{2}{|c|}{ Mating } & \multicolumn{2}{|c|}{ Not mating } & \multirow{2}{*}{$\begin{array}{l}\text { Melanic } \\
\text { frequency } \\
\text { range }\end{array}$} \\
\hline $\mathrm{Nm}$ & M & $\mathrm{Nm}$ & $\mathbf{M}$ & \\
\hline 536 & 44 & 1597 & 88 & $0-10 \cdot 0 \%$ \\
\hline 151 & 43 & 533 & 66 & $10 \cdot 1-20 \cdot 0 \%$ \\
\hline 44 & 20 & 200 & 69 & $20 \cdot 1-30 \cdot 0 \%$ \\
\hline 6 & 4 & 48 & 27 & $30 \cdot 1-40 \cdot 0 \%$ \\
\hline 7 & 7 & 43 & 32 & $40 \cdot 1-50 \cdot 0 \%$ \\
\hline 3 & 1 & 14 & 24 & $50 \cdot 1-60 \cdot 0 \%$ \\
\hline 9 & 23 & 10 & 63 & $>60.0 \%$ \\
\hline
\end{tabular}

Frequencies according to model with constant preferences

$\begin{array}{cccc}\text { Phenotype } & \text { Mated } & \text { Unmated } & \text { Total } \\ \mathbf{M} & m(\alpha+(1-w)(1-\alpha-\beta)) & 1-w-m(\alpha+(1-w)(1-\alpha-\beta)) & 1-w \\ \mathrm{Nm} & m(\beta+w(1-\alpha-\beta)) & w-m(\beta+w(1-\alpha-\beta)) & w \\ \text { Total } & m & 1-m & 1\end{array}$

Fitting data of numbers of ladybirds to models with constant and variable preferences

\begin{tabular}{|c|c|c|c|c|c|c|}
\hline \multirow[b]{2}{*}{$\begin{array}{l}\text { Parameters } \\
\text { fitted }\end{array}$} & \multicolumn{3}{|c|}{ M.L. estimates of parameters } & \multirow[b]{2}{*}{$\begin{array}{l}\text { Log. } \\
\text { likelihood }\end{array}$} & \multirow[b]{2}{*}{$\begin{array}{c}\text { Residual } \\
\chi^{2}\end{array}$} & \multirow[b]{2}{*}{$\begin{array}{l}\text { Degrees of } \\
\text { freedom }\end{array}$} \\
\hline & 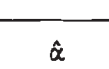 & $\overbrace{\hat{\beta}}^{\lambda}$ & $\hat{n}$ & & & \\
\hline nil & - & 一 & 一 & $-3248 \cdot 847$ & $26 \cdot 207$ & 7 \\
\hline$\alpha, \beta$ & 0.03396 & 0.06110 & 一 & $-3242 \cdot 976$ & $13 \cdot 141$ & 5 \\
\hline$\alpha, \beta, n$ & $0 \cdot 3388$ & 0.4060 & 4 & $-3239 \cdot 414$ & 5.594 & 4 \\
\hline
\end{tabular}

(ii) Data from Potsdam

\begin{tabular}{|c|c|c|c|c|}
\hline \multicolumn{5}{|c|}{ Numbers of ladybirds } \\
\hline \multicolumn{2}{|c|}{ Mating } & \multicolumn{2}{|c|}{ Not mating } & \multirow{2}{*}{$\begin{array}{l}\text { Melanic } \\
\text { frequency } \\
\text { range }\end{array}$} \\
\hline $\mathrm{Nm}$ & $\mathbf{M}$ & $\mathrm{Nm}$ & $M$ & \\
\hline 5 & 1 & 3 & 1 & $10 \cdot 1-20 \cdot 0 \%$ \\
\hline 19 & 11 & 119 & 41 & $20 \cdot 1-30 \cdot 0 \%$ \\
\hline 40 & 44 & 207 & 99 & $30 \cdot 1-40 \cdot 0 \%$ \\
\hline 109 & 91 & 398 & 322 & $40 \cdot 1-50 \cdot 0 \%$ \\
\hline 32 & 27 & 61 & 82 & $>50.0 \%$ \\
\hline
\end{tabular}

Fitting data of numbers of ladybirds to models with constant and variable preferences

M.L. estimates of parameters

\begin{tabular}{|c|c|c|c|c|c|c|}
\hline \multirow{2}{*}{$\begin{array}{l}\text { Parameters } \\
\text { fitted }\end{array}$} & \multicolumn{3}{|c|}{ 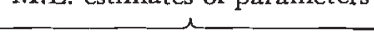 } & \multirow{2}{*}{$\begin{array}{l}\text { Log. } \\
\text { likelihood }\end{array}$} & \multirow{2}{*}{$\begin{array}{c}\text { Residual } \\
x^{2}\end{array}$} & \multirow{2}{*}{$\begin{array}{l}\text { Degrees of } \\
\text { freedom }\end{array}$} \\
\hline & $\hat{\alpha}$ & $\hat{\beta}$ & $\hat{n}$ & & & \\
\hline nil & - & 一 & - & $-2039 \cdot 654$ & $17 \cdot 045$ & 4 \\
\hline$\alpha, \beta$ & 0.4573 & $0 \cdot 5427$ & - & $-2033 \cdot 163$ & $3 \cdot 672$ & 2 \\
\hline$\alpha, \beta, n$ & 0.4603 & $0 \cdot 5397$ & 10 & $-2033 \cdot 073$ & 3.497 & $\overline{1}$ \\
\hline
\end{tabular}


although 1 degree of freedom has been lost. The reason for this can be seen in the original data. The matings in the Potsdam data seem to be almost independent of the population frequencies. The overall ratio of melanics to non-melanics in mating pairs is a close reflection of the ratio of the estimates of $\alpha$ and $\beta$. This means that a great selective advantage is gained by whichever form happens to be at a low frequency. Thus in the frequency range $20 \cdot 1-30 \cdot 0$ per cent, melanics were found to occur at an overall frequency of 0.2737 but were found to be mating at a frequency of 0.3667 . Non-melanics at an overall frequency 0.7263 were mating at a frequency of 0.6333 . The melanics therefore gained a selective advantage over the non-melanics in the ratio $(0.3667 / 0.2737):(0.6333 / 0.7263)$ or $1.537: 1$. However, in the frequency range in which the melanics exceed 50.0 per cent, the non-melanics gained the selective advantage over the melanics in the ratio $1.524: 1$. The approximate constancy in the frequencies of the morphs of mating individuals thus gives rise to sexual selection which is strongly frequency-dependent. The frequency-dependence in the selective advantage is less pronounced in the English data. The difference between the English and Potsdam data is clearly illustrated in fig. 1 in Muggleton's paper (Muggleton, 1979).

If the model of mating preferences is valid for the two-spot ladybird, then sexual selection will certainly produce the stability of the polymorphisms of melanics and non-melanics. Using the estimated mating preferences for the English data and the equation for the equilibrium frequency of the recessive phenotype with $n=4$, we obtain the following equilibrium frequencies:

$$
\begin{aligned}
w^{*} & =0.5617 \text { (frequency of recessive non-melanic) } \\
1-w^{*} & =0.4383 \text { (frequency of dominant melanic) }
\end{aligned}
$$

In the model with constant preferences, the corresponding values would be:

$$
\begin{aligned}
w^{*} & =0.6428 \\
1-w^{*} & =0.3572
\end{aligned}
$$

For the data from Potsdam, we have for the model with constant preferences:

$$
\begin{aligned}
w^{*} & =0.5427 \\
1-w^{*} & =0.4573
\end{aligned}
$$

All these equilibria will be globally stable. The values may, however, be modified by the action of natural selection. It has been argued (see Muggleton, 1978) that melanics absorb solar radiation more efficiently and also that they may be more tolerant of atmospheric pollution. Variation in the selection caused by these factors would of course alter the position of the equilibrium, but its stability would still be determined by the frequencydependent sexual selection.

\section{REFERENGES}

EHRMAN, L. 1967. Further studies on genotype frequency and mating success in Drosophila, Am. Nat., 101, 415-424.

eHRMan, L. 1968. Frequency-dependence of mating success in Drosophila pseudoobscura. Genet. Res., Camb., 11, 135-140. 
Ehrman, L. 1972. Genetics and sexual selection. Sexual Selection and the Descent of Man 1871-1971, ed. B. Campbell, pp. 105-135. Aldine, Chicago.

ehrman, L., AND SPIEss, E. B. 1969. Rare type mating advantage in Drosophila. Am. Nat., $103,675-680$.

MeISSNER, O. 1907a. Die relative Häufigkeit der Varietäten von Adalia bipunctata L. in Potsdam (1906). Z. wiss InsektBiol., 3, 12-20, 39-45.

MEISSNER, O. 1907b. Die relative Häufigkeit der Varietäten von Adalia bipunctata L. in Potsdam (1907). Z. wiss. InsektBiol., 3, 309-313, 334-344, 369-374.

MEIssNer, o. 1909. Die relative Häufigkeit der Varietäten von Adalia bipunctata L. in Potsdam (1908). Z. wiss. InsektBiol., 5, 231-242.

MUGGleton, J. 1978. Selection against the melanic morphs of Adalia bipunctata (two-spot ladybird): a review and some new data. Heredity, 40, 269-280.

MUGgleton, J. 1979. Non-random mating in wild populations of polymorphic Adalia bipunctata. Heredity, 42, 57-65.

o'Donald, P. 1973. Models of sexual and natural selection in polygynous species. Heredity, 31, 145-156.

O'DONALD, P. 1977a. The mating advantage of rare males in models of sexual selection. Nature, 267, 151-154.

O'DONAlD, P. 1977b. Theoretical aspects of sexual selection. Theor. Pop. Biol., 12, 298-334.

o'DONALD, P. 1978a. Theoretical aspects of sexual selection: a generalized model of mating behaviour. Theor. Pop. Biol., 13, 226-243.

O'DONALD, P. 1978b. A general model of mating behaviour with natural selection and female preference. Heredity, 40, 427-438.

o'donald, P. 1979. Genetic Models of Sexual Selection. Cambridge University Press (in press). PETit, c. 1954. L'isolement sexuel chez Drosophila melanogaster. Etude du mutant white et de son allélomorphe sauvage. Bull. Biol. France et Belgique, 88, 435-443.

PEtit, C., AND Ehrman, L. 1969. Sexual selection in Drosophila. Evolutionary Biology, Vol. 3, ed. T. Dobzansky, M. K. Hecht, and W. C. Steere, pp. 177-223. North-Holland, Amsterdam.

SPIESS, E. B. 1968. Low frequency advantage in mating of Drosophila pseudoobscura karyotypes. Am. Nat., 102, 363-379.

SPIEss, E. B., AND EHRMAN, L. 1978. Rare male mating advantage. Nature, 272, 188-189. SPIESS, L. D., AND SPIESS, E. B. 1969. Minority advantage in interpopulational matings of Drosophila persimilis. Am. Nat., 103, 155-172. 